\title{
Moment JoURnAL
}

Journal of Cultural Studies, Faculty of Communication, Hacettepe University 2019, 6(2): 516-544

ISSN: 2148-970X.

Interview

\section{PARTICIPATION, DEMOCRACY, AND CREATING A RADICAL PROGRESSIVE UTOPIA FOR THE 21ST CENTURY: AN INTERVIEW WITH NICO CARPENTIER}

\author{
Derya Yüksek ${ }^{*}$ \\ Nico Carpentier ${ }^{* *}$
}

NICO CARPENTIER is a renowned researcher in the field of communication and media studies. He is an Associate Professor at the Department of Media Studies of Charles University in Prague, with two additional part-time positions, at the Communication Sciences Department of the Vrije Universiteit Brussel (VUB) and at Uppsala University, along with his research fellowships at Loughborough University and Cyprus University of Technology. He was one of the four founding board members of the European Communication Research and Education Association (ECREA) in 2005, the ECREA vice-president from 2008 to 2012, the treasurer of the International Association for Media and

\footnotetext{
* Doctoral researcher at Vrije Universiteit Brussel (VUB), Department for Communication Sciences. ORCID: 0000-0002-6166-1094, derya.yuksek@vub.ac.be

${ }^{*}$ Associate Professor, Department of Media Studies of Charles University. ORCID: 0000-0002-8996-4636, nico.carpentier@vub.ac.be Date of Interview: 10/07/2019.
}

With special thanks to Orestis Tringides for transcribing the English version of the original interview.

(C) Author(s) (or their employer(s)) 2019. Re-use permitted under CC BY-NC 4.0. No commercial re-use. See open access policy. Published by Faculty of Communication, Hacettepe University 
Communication Research (IAMCR) from 2012 to 2016, and the chair of IAMCR's Participatory Communication Research Section from 2016 till the day. His latest books include; The Discursive-Material Knot: Cyprus in Conflict and Community Media Participation (2017); Cyprus and its Conflicts. Representations, Materialities, and Cultures (2018, co-edited), Critical Perspectives on Media, Power and Change (2018, co-edited), Respublika! Experiments in the Performance of Participation and Democracy (2019, edited), Communication and Discourse Theory (2019, co-edited) and Communication as the Intersection of the Old and the New (2019, coedited).

In this interview, held during the IAMCR 2019 Conference in Madrid, Nico Carpentier discusses his multidisciplinary, phenomenacentric approach to communication and media studies, and explains his theorization of participation that tries to restrict the meanings of participation, with references to his 4-level, 12-step analytical model for analysing participatory intensities. In terms of applying these theoretical and analytical insights to empirical settings, Carpentier shares highlights from his recent research on Cyprus - analysing the participatory-agonistic assemblage of a community radio station in this conflict-torn island, and from community media arts festival, Respublika! organized to disseminate the results of this research. While sharing his views on the current worldwide trend of rising antagonisms and authoritarianisms, Carpentier stresses the need to avoid dichotomous models that demonize the relations with the many "others", while arguing for strategies to hegemonize democracy and agonism across all existing parts of society. For him, this requires, on one hand, a "new social contract" for democracy driven by an alliance of all democratic forces, conservative and progressive, and on the other hand, the creation of a radical progressive utopia of/for the $21^{\text {st }}$ century, where intellectuals, including academics, can play a key role. Thanking him once more for this extensive interview, we now leave you with his remarks. 


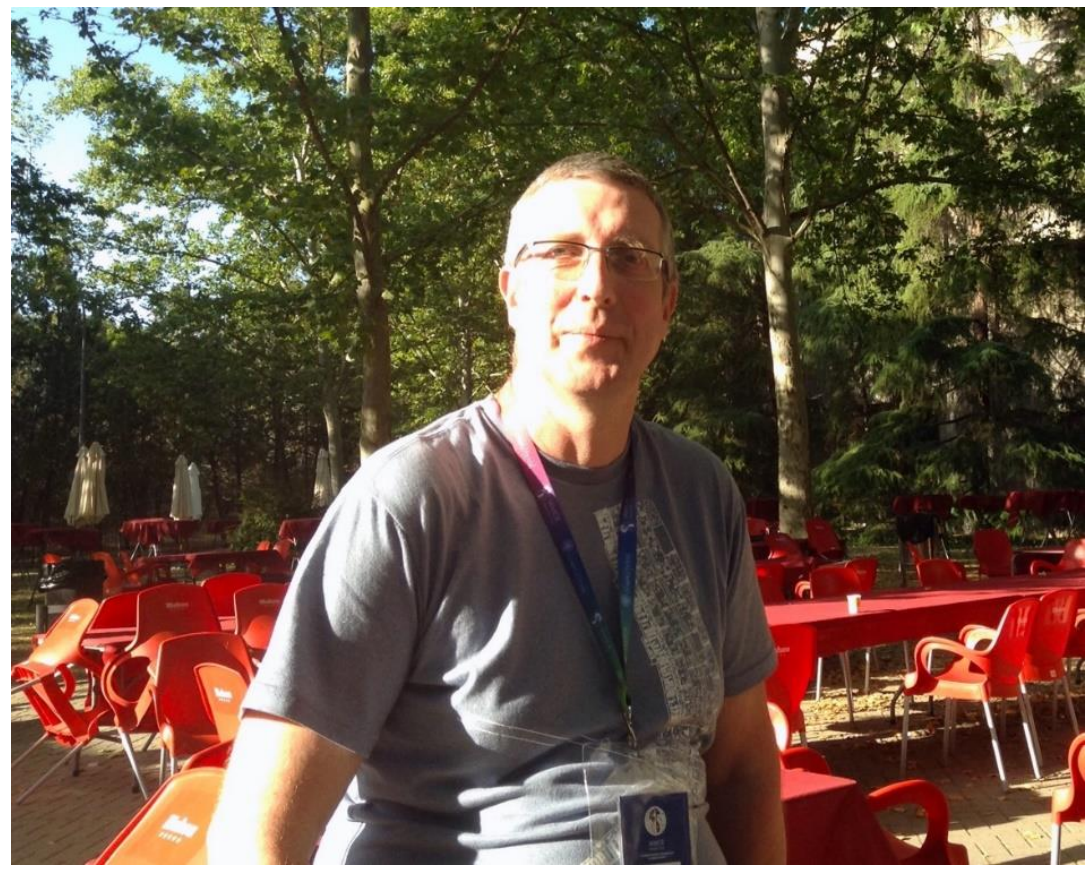

Photo credit: Derya Yüksek

DY: You are a communication and media scholar with research and publications bridging this field with a variety of other fields; political studies, cultural studies, peace and conflict studies ... Participation is one of the central themes in your work. What oriented you towards these fields of research, and to participation as a main area of interest? How do these fields connect in your thought and in your work?

NC: There are two answers to that question. I think one answer would be academic life history, in the sense that, even if I position myself in the field of Communication and Media Studies, I have a fairly diverse background when considering the kind of research I have been doing in the past decades, but also the kind of education I was lucky enough to receive. This has given me the luxury of being positioned in quite diverse fields. Still, there has always been a genuine interest in looking at social processes, communication and their intersections with the political and the cultural. One example there, I think, is all the work that I've been doing in discourse studies, and in particular in discourse theory. But as a consequence, I simply don't want to engage in media-centric research. I do think that media and, more broadly speaking, communication are vital components of the social ... but at the same time, I think that we, in all cases, need to contextualize media, and media research, and that brings us, of course, to society-centric approaches. 
I also don't want to limit my research to the work in our field that is labelled "Media Studies". In that sense, I tend to see myself more as a Communication and Media Studies scholar, with communication coming first ... And exactly that connects me to discourse studies. Because, basically, the interest in the exchange, the circulation of ideas is what is shared by communication studies and discourse studies. So almost automatically, if you look at my trajectory, and the kind of interests I have-the desire to move away from media-centric approaches-it brings me to this broader approach, trying to combine different fields of study. But, there is, I think, something truly important there, which is almost paradoxical. If we choose for this broader approach, and look at discourse studies and the circulation of discourses, at the construction of frameworks of intelligibility, then we have to acknowledge that media are great places to find these discourses. Media are signifying machines that make discourses visible. They (and many other machines) allow meaning to circulate. For researchers, media are a tremendous gift, because they are locations where discourses actually become - what I would like to call-condensated ... they become materialized there. Ideas become very tangible through media; which also means that they can be analysed. Visibility allows for analysis, obviously.

But at the same time, we should not limit ourselves to Media Studies, I think. That's where Media Studies becomes part of the larger field of Communication and Media Studies. And there, I think, the idea of circulation of meaning, which is what communication studies focus on, also allows us to look at so many other processes that are not about media but about mediation, which is something quite different. The concept of mediation is like a gateway, it's one of these doors that opens to a wide variety of other fields. For instance, if you are interested in the construction of death (Carpentier and Van Brussel, 2012), you can look at death and the way we think about death as a discursive-communicative practice. And then, all of a sudden, you find yourself capable of doing research that combines the different fields, that indeed looks at the discursive-communicative component, but that also looks at the sociology of death, at the history of the ways our particular societies have been dealing with death and dying. And, in a way, these are the doors that are opened through the concept of mediation ... Once you enter through that door and discover Death Studies (as it's called), you'll find this intersectionality in approaches that only tempts you, and challenges you, to expand further. 
This first part of my answer was based on an academic life trajectory. But - and this is the second part of my answer-this approach of Communication and Media Studies cross-fertilized with discourse studies almost forces you to look at phenomena. Of course, we have media-centric and society-centric approaches ... That's often used, but I would like to move away from this dichotomy and add the phenomena-centric approaches to the list. In these approaches, you start thinking from-and about-a particular phenomenon. And that allows you to then mobilize particular disciplines, fields of knowledge, to start analysing that phenomenon. Media will always be part of this approach, communication will always be part of this approach, I'm sure. But, just not necessarily always at the centre. As society-centric approaches could basically mean anything, focusing on particular phenomena, particular themes, particular social processes allow you to move in-between these two "centrisms" that we so often distinguish and actually creates a third option: a phenomena-centric approach.

DY: Thank you! Interesting!

NC: It's just the first answer. (smiles)

DY: Yes! Coming to participation ... Here, I'd also like to refer to the JenkinsCarpentier conversations. Your earlier conversation on participation and politics (Jenkins and Carpentier, 2013), which also inspired this issue of the Moment Journal, has recently been rekindled in Jenkins' blog, under the title "Participatory politics in an age of crisis" (Jenkins and Carpentier, 2019a). On both occasions, you clearly opt for a restricted definition of participation and distinguish between minimalistmaximalist forms, linking the concept to substantive democracy, civic learning, participatory leadership ... Can you explain our readers a bit more of this approach towards participation, which also developed into an analytical model recently? How does it connect to the overall approach you have just explained? What does it imply for media participation and communications media research? And how does it link to new media and participation debates?

NC: That's about five questions. You will have to remind me along the way...

DY: Yeah! Sorry ... first, your approach towards participation...

NC: Let's start with the very basic idea that my work on participation is an illustration of this phenomena-centric approach. It is based on the idea that we have to study a particular phenomenon: Participation, which is also about a particular signifier: the 
concept of participation. And of course, that phenomena-centric approach forces me to look beyond media and participation. It forces me to look at how participation is deployed in a wide variety of fields. And if you look at the Media and Participation book (Carpentier, 2011) and in the one-hundred-plus pages of the theoretical framework-I did get carried away a bit (smiles) - you'll find that media and participation (and media participation) are important ... but there is a whole range of other theoretical subfields that are discussed in that book as well. There is, for instance, a discussion on democracy, and how a democratic-theoretical perspective looking at participation can help us. There is a discussion on arts and participation, there is a discussion on museums and participation, there is also a discussion on development and participation. It is exactly this broad approach that has fed my thinking about participation, by not looking at the discussions about media and participation in isolation from what other fields have been doing. And that's where my fascination resides because once you start looking at all these fields, participation is always there! All these different disciplines and academic fields, they all have discussions about participation, which is fascinating in its own right. It's like walking through the garden and turning upside down one stone and discovering a discussion on participation ... And then finding another stone-another field-and opening it up... and finding yet another discussion on participation. So it's like this little exploration through the world of academic knowledge, always finding these discussions, as long as you take the effort of turning the stone and looking what's underneath. That is something that has really structured my approach to participation. It's not developed in isolation, in an only-andexclusively Media Studies approach - on the contrary.

This strategy also allowed me to see the differences and similarities in these fields. It produced, for instance, the basic categorization of participation-as-taking-part (the sociological approach) versus participation-as-sharing-power (the political studies approach), partially also inspired by Lepik's (2013) Ph.D. thesis. A lot of research tends to lean towards the sociological approach ... thinking about participation as taking part. I very explicitly wanted to stay away from that approach, and to move closer to the political studies approach, which has a much more focused definition of participation, as the decentralization of power relations, as sharing power. For me, that is a second, and very different, approach. I don't want to discredit the first, sociological approach, though. But I am simply not comfortable, theoretically comfortable, with the idea that participation can be ... anything. I'm not comfortable with the idea that every form of 
social interaction can be labelled "participation". Hence my move towards a more restrictive definition of participation, which brings us with the notion of the decentralization of power relationships, combined with, firstly, an emphasis on decision-making, formal or informal, and secondly, an emphasis on actors that take these decisions in particular power constellations, who might become more privileged - or less disprivileged - through these participatory processes.

And that is the approach I am comfortable with, in the sense that I want to focus and zoom in on this more focused and less all-encompassing definition of participation. Which then leads us to the Jenkins debates, in the sense that this is absolutely crucial in trying to understand how broad or narrow participation has to be defined. But, also, if you accept a narrower definition, then how to deal with the question that automatically comes up: if something is not participation, what is it then? If participation has limits, what are the limits? Where does participation stop being participation? And that was very much part of the first debate with Henry [Jenkins], in the sense that the big question was where to draw the line and how to avoid that everything becomes considered participation. The concept of participatory culture, that Henry has been using, produced the impression that everything was now participatory, and that we were living in a participatory culture. While my theoretical contribution to that debate would be to at least add a warning to that concept, that one should be a bit careful not to create the impression of a ... in French they have the wonderful word, "le fait accompli" - " the accomplished fact" - to refer to something that has been consolidated. It felt a bit like the Fukuyama "End of History" debate (without wanting to equate Jenkins and Fukuyama), where after the fall of the Wall, capitalism had conquered the world and history had come to an end. Participatory culture, as a concept, sounded as if we had reached this point. While what I wanted to argue is that we need to contextualize participatory practices, seeing them as part of a potentially growing democratic culture and the continuation of the democratic revolution.

If we look into the changes over the past centuries, we definitely have to acknowledge that participatory-democratic levels have increased. But at the same time, we should still consider the idea that we're not there, that we have not reached the point of maximalist participation. I actually think that we can never reach the hegemony of maximalist participation: It is a utopian concept, necessarily outside our reach. We might want to try to get closer, but it is structurally unreachable. It is ... phantasmatic, or utopian, whatever theoretical framework you prefer to label this unreachability. That 
was what the discussion with Henry-actually, the first discussion-mostly focused on. And to continue, because I can talk about this endlessly, obviously (laughs)... Once you start arguing that maximalist participation, the total decentralization of power is utopian, then, of course, you start thinking about participatory intensities, you start thinking about moments, situations, contexts, where a certain degree of participation has been achieved. They might not be maximalist participation, but they might be close to maximalist. Or they might not even be close to maximalist, making them more minimalist. But we need to think about participation as a dimension with different participatory intensities. In short, the idea that participation has different intensities allows us to think about participation as a process that spans between something that is very minimalist, and on the other hand, something that is very maximalist.

But we also have to acknowledge-and that is what the political studies approach allows for-that sometimes participatory practices are labelled "participatory practices", but that they are not participatory at all, not even in a minimalist way. They are simply something else. And then comes a very important disclaimer: It's not because they are something else that they're wrong, or evil, or undesirable. I tend to distinguish between participation, interaction, and access. It doesn't mean that access is wrong, or undesirable. It doesn't mean that social interaction is necessarily wrong, or undesirable. Interaction is simply something else than participation. So I don't want to create and defend a prescriptive model where only the few practices of power-sharing, radical power-sharing, are considered to be desirable, and all the rest is undesirable. That's not how it works for me. What I want to argue for is that we need to understand participation better, looking at the wide range of options that fall within the definition of participation, but also be very clear that sometimes social practices are outside the dimension of participation and thus simply something else. And that's where the discussion with ... the second discussion with Henry actually builds on. Looking at, then, these questions about the limits of participation.

\section{DY: What motivated you to engage in this new discussion?}

NC: Yeah ... there are a couple of things. One, what Henry wanted to do now, in 2019, was to launch a series of broader conversations. And there are many wonderful conversations - if you go to his blog or to its archive you'll find over 20 of them. This was the format that he wanted to use, which I thought was quite exciting. Also because when in 2013 we developed this model of a conversation as a way of structuring our thoughts, I genuinely think both of us really liked it and enjoyed it. Not just a 
conversation between the two of us, but also the format of the conversation. It is not a conversation that got transcribed afterwards; the text is written with and through the conversation itself. In this case, he wanted to organize a very blog-driven conversation, so the interface really mattered here. There is much respect for the visual, I think. And our conversation is part of a series of conversations, which contextualizes it. Henry also wanted to go back to the topics of that original 2013 conversation and when he was setting up the pairs-because all conversations were organized in pairs - he contacted me, explained the format and said like "well, would you mind doing this one with me?"

I was more than happy to accept, because, of course, this was six years later. Our thoughts have evolved and we've been dealing with quite a number of newer issues. Leadership, for instance, became important for me, as it is one of the key subject positions that can have a substantial impact on participatory processes, but also because it is performed in material practices. Ethics also became more important, because I think that we need to start thinking about what participatory ethics actually means. I still like to argue that participation, in itself, is ethical. More specifically, using a discursivetheoretical framework, I would argue that there is a wide variety of normative frameworks that compete with each other over the empty signifier of the ethical. This implies that we need to actively defend and even propagate the participatory normative framework, which articulates participation, the sharing of power, as ethical. To put it in very simple terms, I strongly believe that the decentralization of power is an ethical position. But then, if we want to talk about participation in these ethical terms, we need to develop that language, and we haven't done that sufficiently. That was one of the issues that were raised during this conversation, based on the way that our thinking has evolved. And, of course, also in Henry's case, things have changed. He has been working in many different fields. Originally, I think his reputation was based on his work in fan studies, and rightfully so. But he also got interested in a wide variety of participatory practices in different fields, which include pedagogics and politics, to name two significant expansions of his field of interest, which also brought about new questions. If you start talking about political activism-as he did later on-it is still connected to fan studies, yes, but it also opens up a wide variety of doors and new questions. He has been expanding his agenda quite fundamentally, which made it fun to organize a conversation, knowing that our thinking, but also our fields of interests, had evolved in these ways.

But your question had many other questions... 
DY: Your approach to participation ... I was asking, what does it imply for communication and media research? In part, you answered that...

$\mathrm{NC}: \mathrm{Oh}$, but there is a more extended answer possible (grins)...

DY: Yes ... Can we relate your answer also to the New Media and Participation debates? Where do you put your approach in these debates?

NC: It's an interesting and difficult debate because I want to acknowledge the research and the importance of the research that has been done on digital media. I don't want to sound negative in any way. If we, at the same time, analyse the fashions in our field, it's sort of hard to miss the point that the study of the digital has driven our field forwards. But we should also see that the rather exclusive focus on the digital has generated a number of problems.

Let's start with the first part: The focus on the digital has indeed driven our field of communication and media studies forwards. It has made a large number of people, in the most general meaning of that term, interested in digital media and it has made a large group of people interested in participation, in and through digital media. It has been a key driving force-that is utterly significant-in making participation visible again. Participation became popular again, as a field of study, thanks to the (study of the) internet, to use a short-cut. But, the other side of the story is that it has created a series of myopias. It has made us blind to a wide variety of other social practices. The fascination for the digital generated a preference for studying it, spending much less attention to other fields of the social. We are too blind for what is not changing, hidden by the technological changes. Or, in other words, we're ignoring hegemony too much. What I think we are now creating, if we haven't done so already, is not so much a media-centric approach, but a digital-media-centric approach, which is even more reductionist than the media-centric approach ever was. I don't think that that's a wise strategy. Of course, if people wish to engage in media-centric research, who am I to advise them not to? But we need a better balance of research that is digital-mediacentred, that is society-centred and that is phenomena-centred. Because we are literally blinding ourselves to a wide range of social practices that should fall within our field of interest, but that somehow aren't fashionable enough. This is the price you pay for fashion. (smiles) We have entered into a ... not so much a technology-deterministic trap-I think we fell for that originally, but nowadays we are more careful-but a digital-media-centric trap. It seems to me that if you want to do research, get research 
funded, to trigger attention and interest, you need to do digital media studies. And I am not too sure if this is a wise and good thing to happen. Again, to go back to what I said, this is not to discredit the research of people that are interested in this part of our field. It should remain part of our field, but we need to establish a better balance.

Taking this back to our discussion on participation: I think this is the context in which we are currently operating. Participation has become fashionable, in the slipstream of the fascination for what was first called "new media studies" ... which we wisely have stopped using, now labelling as "digital media studies", which is already quite nice-and an improvement for sure. But, we should be careful to prevent that, when the fashion blows over, and other issues come to the fore, we stop thinking about the decentralization of power. That's why we need to disconnect this automatic link between digital media and participation. It is a vital field for studying participation, but we should be very careful not to cut off all these other fields, that also offer participatory logics and that also are legitimate fields of study in thinking about participation. That's one of my main concerns.

The other, and related, concern is that new fashions have come up. There is something that has triggered our interest, which is, between quotation marks - and I repeat, between quotation marks (smiles) -"fake news". I'm not too sure whether it is good to have US presidents coin a term that then gets accepted as an academic concept. And I think we need to distinguish between fake news-you know, what was once called (black) propaganda-and "fake newsing", the strategy of attacking news media in an attempt to discredit them. But all this is beside the point I want to make here. (smiles) That point is that some of the discussions about fake news actually run the risk of producing a problematization of participation. All of a sudden, participation becomes, at least partially, dark participation, it becomes seen as something that is problematic, as if the redistribution of power is bad in itself. Interaction can be problematic, yes. The consequences and outcomes of participatory processes can be problematic, yes. But participation itself? The redistribution of power itself? I see no darkness there. I only see people that want to switch off the light.

I'm not too sure if we are doing a service to the logic of participation, and to academia that is studying these participatory logics, if we blindly follow these new fashions, and focus on how problematic participation is. There is a need to look better at the relationship between fake news and participation, to theorize it and think it through properly. But we should not go into the creation of a new unique relationship between 
two concepts, participation, and fake news, as we did before with participation and digital media. It is always good to see that there is a new interest in participation, but it is an interest that brings about a whole range of problems and threats.

DY: Oftentimes you refer to the complexity of participatory processes and the need for an intellectual strategy to study these practices critically. In your opinion, what kind of methodological choices and analytical strategies may support this kind of research?

NC: Well... Going back to the distinction between the sociological approach and the political studies approach: Choosing for the sociological approach is actually a way of making things methodologically and analytically very easy. Because if everything is participation, then there is no necessity for an analytical framework that is nuanced and sophisticated because then things are very straightforward. Then you actually do a type of sociology that has been done for decades, and there is nothing wrong with that. But if you take the other route, the political studies approach towards participation, which has that very particular and restrictive definition of participation, as we discussed before ... if you take that route, there is a much stronger need for developing analytical procedures to study participation. What I've been trying to develop is an analytical strategy that allows you to think through the different steps that you have to take to understand participatory intensities. That article (Carpentier, 2016) was very consciously written to produce these research guidelines based on my own research experience and all the complexities that I (and others) ran into.

The core idea of that analytical model is to have 12 steps. But for everybody's sake (smiles), it would be easier to discuss the four levels that structure these 12 steps. These levels are the different components that need to be studied. The first level tries to understand that participation is always connected to a particular process that is embedded in a particular field. Participation is not outside context, after all. We should avoid very generalist statements when talking about participation. In contrast, participation is situated in particular processes and these processes are in turn contextualized by societal fields. To give an example that illustrates these different processes and fields: If we go back to Digital Media Studies, there is a structural difference in studying the process of participation in the company Facebook, and participation through a particular Facebook group in another field: in politics, in nature preservation, in artistic creation, whatever. We need to be careful outlining these processes and the fields in which they are embedded. That is the first level, and the 
starting point: You need to decide what exactly the object of analysis is and what the context of that object of analysis is. Quite straightforward, actually.

And then come the other levels that structure the 12 steps. One is connected to decisions, and the third one is connected to actors. When analysing participatory processes, you have to acknowledge that participatory processes involve groups of actors that find themselves in particular power situations in society. Some of these actor groups are privileged or more privileged, others are disprivileged or less privileged. These actors, engaged in participatory processes, find themselves situated in societies that actually offer them particular power positions to act from. For instance, if you look at homeless people-an example of research I have been more recently involved in (Carpentier and Doudaki, 2019a and 2019b)-they find themselves in radically disprivileged power positions in society. If they become part of a participatory process, the objective of that participatory process is to empower them in relation to other actors that are in stronger power positions. A lot of analyses that deal with actors engaged in participatory processes tend to shy away from these questions of the actors' - between quotation marks - "original power position", and how a particular participatory process is then trying to alter that. This means that the identification of these actors, the identification of their "original power positions" in society, and the way that a then participatory process tries to change those original power positions and to empower the more disprivileged actors, all these are crucial questions at the level of the actor.

The third level is the level of the decision. Because participatory processes involve a wide range of decisions that are made by the involved actors (who were identified at level two). It's a matter of trying to define and analyse which decisions are being made in this participatory process. Mapping the actors and their decisions is fairly complicated because-in particular in the case of the decision level-there is an immense quantity of micro-decisions that need to be analysed. Once you engage in mapping these micro-decisions - in similar ways as has been done with the actors-you need to categorize them, you need to cluster them to be able to speak about this multitude of micro-decisions. This is quite a challenge, and sometimes there is a need to keep individual actors in mind, but participation is very much about the power imbalances between actor groups that are then redressed through the participatory process. If, for instance, you analyse audience discussion programs, it makes sense to look at the production team as an actor group-and keep the role of the host in mind, as 
a member of that production team, who also stands out-and the power relations with other actor groups, such as ordinary participants, experts and celebrities.

The fourth level is bringing everything together and doing the actual power analysis. That is-obviously-why this level's keyword is "power". These last steps consist of looking at how particular actor groups can weigh on particular clusters of decisions, and how different actor groups are actually empowered, or not. In particular, of course, this level focuses on the disprivileged actors, trying to see how they are involved, how they can co-decide in these particular clusters of decision-making, and how they become empowered (or not).

Combining these different analytical levels then allows researchers to come up with an analytically-grounded conclusion that addresses the main question, which is the way(s) in which original power imbalances in society are corrected by the particular participatory process that is analysed. In some ways and in some cases and some periods - to bring in the notion of time-you might conclude that the way that power imbalances have been addressed and redressed is minimal. You will have to - in some cases-conclude that there are possibly a few restructuring elements that change that power relationship between disprivileged and privileged groups, but there still is not that much change to be found. While in other cases, you would be able to argue, based on the analysis, that there is a substantial change in the power relationships in that particular process, which then allows you to speak about more maximalist participation.

These are, for me, the four levels of participatory analysis. If you unpack the four levels, there are actually 12 steps that you can go through. But, there is a thirteenth step, which is only addressed in the conclusion of the "Beyond the ladder" article. Because, after having gone through the 12 steps, the question that then comes up, is what to think about all this. You have a particular process, embedded in a particular field, and you have reached a particular conclusion about the participatory intensities of this process. This conclusion can, for instance, say: "This process as a whole is fairly minimalist" or "this is a hybrid process with some of the sub-processes being more maximalist and others more minimalist". Or you could reach the conclusion that this is a fairly maximalist process or a very maximalist process. The thirteenth step is then raising the normative question: "So what? Is this good? Is this problematic? Is this desirable?" Maybe in some particular cases, in some participatory processes, it's better to have more minimalist versions of participation, while in other cases, the opposite could be argued. 
The thirteenth step adds a normative dimension to the analysis, trying to evaluate whether a particular outcome is desirable, or not. This is a significant addition to the twelve-step model. But it's a separate step, because it's a normative evaluation of the outcome, while the first twelve steps aim to be analytical. So in short, the first 12 steps aim to understand how particular power relationships are altered through a particular participatory process, and the $13^{\text {th }}$ step then evaluates that outcome.

DY: Coming to your latest monograph, the Discursive-Material Knot (Carpentier, 2017) that involves an empirical study on community media in the conflict-torn island of Cyprus and their role in conflict transformation ... Could you give us a bit more information about this book and the research behind it? We would also like to learn more about the community media arts festival "Respublika!" which presented an unorthodox way of communicating the results of this academic research...

NC: The DMK, or the Discursive-Material Knot-somehow, I'm a bit lazy about the book's title, so I refer to it as "DMK" (laughs)-offers a particular ontology of entanglement. That's the starting point. It tries to understand how both the discursive and material worlds interact with each other-how they are always knotted together in theory, but also in assemblages of concrete social practices and processes. I can talk about this model forever because it utterly fascinates me, but here, I will not try to focus too much on the theory of entanglement behind the DMK. But, it is for me an important framework of thinking participation, so allow me to explain the model of the DMK a bit. Originating from, and starting from, discourse theory, the model of the DMK tries to theorize the relationship between the discursive-object of political interventions that try to hegemonize and sediment them-and the material world, in a context of contingency. We should keep in mind that discourse theory always acknowledged the existence of a material world, but it didn't treat that material world in a very balanced way. To be more accurate, when it came to actual levels of attention, discourse theory was mostly interested in how discourses functioned, always acknowledging the existence of the material, but not creating a non-hierarchical relationship between the discursive and the material.

My project was (and is) to add a new materialist component to the equation, in order to strengthen the discourse-theoretical tradition. As the label ("DMK") already indicates, the project is deeply interested in the material world and inspired by a new materialism, but wishes to reconcile it with the always-knotted discursive component of that world. And so, bringing these two together allowed me to think about the 
discursive and the material as entangled, as knotted together. I should add that this knot is not a Gordian knot. It is not something where you can take a sword and slice it into pieces. Maybe similar to Medusa's head-if you want a metaphor-it has a movement that articulates and rearticulates discursive elements with material elements, even if it can appear (and sometimes is) quite stable at times. It is an always-potentiallychanging assemblage that, in itself, is again the object of political intervention, which tries to fixate and sediment it. But it moves, unavoidably, not permanently, as there is always the option of contingency being enacted.

This framework allows me to think about participatory assemblages. I use the notion of the assemblage to talk and think about how the discursive-material knot is performed in actual social practice. How it is translated, so to speak, in actual social practice. There are many different kinds of assemblages throughout the world, and one metaphor that I use, to better understand the assemblage is the "matryoshka doll gone wild". As you know, the matryoshka doll is the doll, within the doll, within the doll. Quite similarly, assemblages are assemblages inside assemblages ... To use a military example, the tank is an assemblage that is part of a much larger assemblage called "the army". But as a metaphor, this is too clean and too contained, which is why I refer to the matryoshka doll gone wild: There are overlapping assemblages, there are assemblages that are partially included, partially excluded, etc. It's much more a messy rhizomatic ensemble of assemblages, a huge network of micro-assemblages and macroassemblages, all interacting with each other. That doesn't necessarily mean that we have to analyse all of them, all at the time, we can, of course, make choices to analyse particular assemblages.

For instance, there are participatory assemblages. These are assemblages that combine discursive elements-"signifying practices" as I call them-and material components-bodies, objects, ... If we talk about community radio, we talk about electricity, we talk about studios, we talk about technologies, we talk about producers, their bodies, their hands, the fingers of producers ... Technologies that have their own logics, their own agencies. Things do things. They sometimes break down ... Sometimes ... It's a banal example, but it's significant, having worked in community media myself for years: Sometimes if you play a vinyl record, the needle will jump. This is not a conscious intervention, but that jump can then be integrated into the actual production of a radio show, and you can play with that. Still, it simply happens. That's the agency of the record player interacting with the vinyl. It does things, it has its own agency. And 
all of this needs to be integrated into our thinking about participation, as participatory assemblages. Often, we have not paid attention to this assemblage as an assemblage. Often, when we were talking and thinking about community media, for instance, we were so very much interested in their broadcasts. Or, we were so interested in these material practices of power-sharing, decision-making. My point would be that we need to pay more attention to the articulation of these discursive and material elements in these participatory assemblages.

That brings me to Cyprus. In my work, I like to combine theory with empirical research. I have no hierarchy, I like both, and I like to integrate them as little assemblages in their own right, of course. And that integration, for this particular book, brought me to Cyprus and the study of CCMC - the Cyprus Community Media Centre, and its radio station MYCYradio ... which had two main objectives: to organize participation and to contribute to conflict transformation. Which made them a fascinating participatory-agonistic assemblage, the label I'm using in the DMK book. It is an assemblage that organizes participation. It is an assemblage that organizes agonism. It does both. This organization is a material-discursive assemblage with particular objectives, to organize participation and to contribute to agonism.

That case study - because it is very much a case study - was deeply interested in understanding the MYCYradio radio station and the CCMC umbrella organization as a participatory-agonistic assemblage. I was interested in critically analysing how this assemblage functioned, how its different elements came together, for instance, driven by discourses on democratization, participation, agonization ... which are, of course, significant ideas, but they are combined with material components with, for instance, a wonderfully warm little container building in the Cypriot Buffer Zone. These materials bring about their own context, as part of this assemblage, with the studio that had a particular size, and that was a space with its own affordances.

This case study also made it possible for me to enrich the theoretical reflections about the discursive-material knot. So that first theoretical platform - as it's called in the $D M K$ book - was actually created in interaction and in iteration with the CCMC case study. The case study also allowed me to develop the second platform, which deals with the reconfiguration of participatory theory, community media theory, and conflict theory, from the perspective of the discursive-material knot. But always cross-fertilized with the CCMC case study, which was vital, not just as a research project in itself, but also as a foundation for the theoretical work and a challenge for the theoretical work, 
through the logics of the iteration. The outcome of that research project, at the level of Cypriot community media and conflict transformation, was indeed the acknowledgement that participation and agonism strengthen each other. They allow each other's intensification, where participation contributes to agonization and where agonization actually also allows for participation. And that combination, that articulation, I think, is vital. In many cases, when conflict transformation is being organized, participation is not that high on the agenda. I would say that the integration of these two ideas might actually strengthen efforts for conflict transformation - at the same time serving the agenda of the democratization of these societies that still find themselves confronted with violent conflict and that are in dire need of both agonization and democratization.

After the publication of the DMK book came Respublika!. There is a chronological narrative here in the sense that these are the actual steps that I took. Once the DMK book was finished, there was the question of what to do with this book. Academics have this tendency of then arguing "I need to go out and talk about the book", "I need to present the book", "I need to share my thoughts", which brings about many conference presentations, possible follow-up publications and a variety of informal conversations. Of course, I did do all that, but I found it insufficient. This was also because the $D M K$ book was created using participatory research methods. Particularly the third platform, about CCMC, was created in a research cooperation with the CCMC itself. They were involved in the actual research about themselves, as researchers, trained by me. Obviously, I did not treat the CCMC people as research objects. But I also wanted to do more than treating them as research subjects. This implied that I was involving them, training them, and having them cooperate with me, as researchers. I did find it important to maintain the final responsibility for the outcome, but also this was done in consultation, in dialogue and, more importantly, in collaboration with the CCMC.

Having gone through all these stages, with their participatory research component, and finally having finished the book, it felt awkward to then just go back to academic business as usual and just do the "normal" academic set of presentations. What I wanted to do instead, apart from all these obvious things that I still did, of course ... what I wanted to do, was to create a platform where community media activists in Cyprus could then communicate their take on a key idea of the book - their 
importance for democratization and agonization - to the world, to Cyprus, to other Cypriot citizens, but also to other communities throughout the world.

And that's where Respublika! kicked in. Respublika! was an art project which combined three exhibitions, a one-week arts festival and a whole range of other activities (for instance, a seminar series). It was a big and exhausting project, organized in collaboration with $\mathrm{NeMe}$, a Cypriot arts centre, CCMC, and several other partners. And it allowed me to create a platform where community media activists could communicate their importance, not necessarily only using the book as the channel of communication, but creating a new communicative platform that would, in differently accessible ways, communicate the importance of community media in Cyprus. In practice, Respublika!'s basic idea combined two objectives: to create a platform for participatory arts, and to create a platform for arts that thematised participation. In particular art works, these objectives became sometimes combined and balanced, sometimes they were not ... Behind all this was, of course, a choice for an artistic repertoire. This meant that, together, we could communicate the outcomes of the DMK study in a very particular way, in a particular context, bringing it to the artistic field, with all the advantages and disadvantages that that kind of choice brings about.

Respublika! brought together 18 wonderful art projects, and allowed me-in collaboration with many others - to communicate the outcome of the DMK study using a non-written textual repertoire, and to bring that kind of knowledge to audiences that had not that much to do with academic research. These 18 projects were incredibly diverse, and they all, in their own ways, allowed us to speak about participation and/or peace, in a Cypriot context, but also outside that Cypriot context. Respublika! was also a way of trying to find other ways of communicating and generating academic knowledge, inspired by art-based research practices, which actually acknowledge the arts as a field of generation of knowledge and not only as a channel for communication. Obviously, it is. (smiles) Inspired by this art-based research tradition, I was able to organize these events that would communicate the results of the DMK study, and add to it, with new insights and a bit of new knowledge.

One of the eighteen art projects, the Mirror Palace of Democracy, is particularly important in this context. I decided to do more than merely curate the Respublika! project, and added one installation of my own. That became the Mirror Palace of Democracy installation, which was a theoretical reflection about the contingency of 
democracy (Carpentier, 2019) ${ }^{1}$... It used the maze of a mirror palace as a location and a metaphor to think about democracy as a confrontation of ideological struggles. The mirror palace installation had different voices inside, through 5 videos, that each offered particular ideological frameworks, for instance, militarism or solidarism. Playing them together, in a mirror palace, created an auditory and visual cacophony, showing the contradictions, the struggle, and the contingency of democracy. But by creating this installation, by offering it to an audience that could physically enter and experience democracy's ideological contradictions, I not only communicated some of the results of the DMK study, I also generated new questions that then contributed to my own thinking about democracy, participation and the discursive-material knot.

\section{DY: Will we see these in a written form? Your reflections?}

NC: The first article is in preparation. (laughs) It's a good question and I will answer it more seriously, though. An art installation is a discursive-material assemblage in its own right. But every assemblage has its own characteristics and an art installation is deeply material. The Mirror Palace of Democracy invited visitors into a maze of mirrors, see-through panels and voices to experience this theoretical reflection about democracy, and the cacophonic effect of these five videos in a mirror palace, which were written (projected) on the bodies of the visitors ... Then, using a different language-such as an academic article - to communicate about it is extremely difficult. I did produce a short film about the Mirror Palace of Democracy, which can also be found on my website. But that film will never be able to capture the embodied experience of entering the Mirror Palace of Democracy, exposing oneself to these five ideological voices, in an environment that is reflexive in the most literal sense of the word. Producing a written text about the Mirror Palace of Democracy is another way to contribute to the Mirror Palace. In a way, it is another Mirror Palace, but it can never do justice to the Mirror Palace as an art installation. This is part of the problematics of shifting communicative modes when analysing and showing the contingencies of democracy and its ideological struggles. Nevertheless, it can be added, it is another mirror palace that can, and hopefully will be, created.

\section{DY: We are waiting!}

1 This is an introductory article on the Mirror Palace of Democracy, including some of the installation photos, which has been included in the festival catalogue, Respublika! Experiments in the Performance of Participation and Democracy (2019), available online at http://nicocarpentier.net/respublika/. 
NC: Yes ... I am on it ... (smiles)

DY: Moving from Cyprus to Turkey, a country with a general minimalistic understanding of participation and rising authoritarian tendencies in the realm of politics ... and which is situated in an increasingly authoritarian regional and international context. How to promote and enhance democratic participation in such a country? In your conversations with Henry Jenkins, you point at the need for maximalist participatory practices, situated at subcultural- and micro-levels, enforced through strategies that connect different struggles of social movements and participatory organizations, as a general formula ... Do you think this formula could apply to the Turkish context? And how?

NC: May I comment that the answer to your question is in the question itself? (laughs)

DY: This is the formula, yes. (laughs) But could you tell about your thoughts specifically?

NC: It's tempting to say "yes". Because I agree, obviously.

DY: Or, what kind of a role media participation can play in this change?

NC: Ok, more seriously (grins) ... I think the question and the answer embedded in the question makes a lot of sense, although I wouldn't call myself an expert on Turkish politics. Still, in Turkey, we are confronted with a very particular political context. We should keep in mind that the desire for democratization and agonization, which does exist in this country, is often frustrated by this context. At the same time, we should always be careful not to demonize particular regimes. We should analyse them, and we should definitely critique them, but not in replicating a dichotomous model that celebrates the West and demonizes Turkey. We should be academic in our analyses. And that means our analysis should be sharp as a razor blade, but simultaneously characterized by fairness and honesty, not driven by what one has to call neo-colonial and orientalist frameworks.

We should not take the easy way out. This is not the same, though, as saying that there are no problems in Turkey, obviously; when we are taking this lens of the combined desire for democracy and agonism, Turkey is not doing too well. (smiles) The question then becomes how to deal with these aberrations, and more in general, how to deal with non-democratic and non-agonist settings, keeping again in mind the need to avoid simple and reductionist dichotomies. I would argue that behind your question 
and the beginning of my answer-which is the starting point of my response herethere is the desire to hegemonize democracy. And the desire to hegemonize agonism. Obviously, this is a normative position. But it is mine ...

Some people deeply enjoy war. I don't think that I agree with that position. Some people deeply enjoy dictatorships - usually the dictators themselves (laughs) ... and their followers, not to forget. There is intense pleasure generated by dictatorships and intense pleasure generated by war-the problem is, only for some. Others are subjected to deep traumas created by the combined absence of democracy and peace. I prefer to see these traumas avoided, which leads me to-and I should be transparent about this-argue for the hegemonization of democracy and agonism. Everything, for me, starts from there. Every remediation of what we define as a problematic situation starts from that normative position. It has to. But we should, at the same time-and this is the discursive-theoretical me speaking-very honestly acknowledge and consider that some people deeply enjoy a different model that is non-democratic and non-agonist.

This brings about the idea that in these regions, and actually in all regions in the entire world, we find ourselves in a struggle between different forces. Some are defending more democratic practices, others more non-democratic practices. Some more agonist and others more antagonist practices. This is a political struggle. Sometimes that struggle itself is democratic, sometimes it is not. Some struggles are intensely violent, as many revolutions have demonstrated ... other struggles are quite peaceful, sometimes even harmonious, as a discussion among friends, so to speak. We need to take that diversity into consideration, and the idea of the existence of a political struggle between different ideological positions in relationship to democracy and agonism/antagonism.

Now, once you acknowledge the existence of that struggle, you can actually start thinking about methods of intervening in that struggle-that's the next step. And then I would argue that one of the many possible strategies-keeping in mind that many authors have written about this and that I have no intention of producing a full overview of these strategies - consists of strengthening participatory assemblages. More accurately: strengthening participatory-agonistic assemblages.

One mistake that is often made in these discussions is to see a particular country (like, e.g., Turkey) from a mere regime-versus-people perspective. Or even worse, from a leader-versus-people perspective. This is a very state-focused approach, which ignores the problematics and complexities of popular support ... These perspectives 
need to be complicated because they are grounded in a linear model that pitches the leadership versus the people, which is just unacceptably reductionist. If you want to understand these political dynamics, you have to move away from unilateral relationships and move into a multilateral set of relationships. We have to acknowledge that sometimes peoples are pitched against peoples, communities against communities, who all create their alliances.

This structural analysis is important, also from a participatory perspective, because the linear model allows for arguing that democratization of a particular society consists of the removal of a particular leadership. In the linear leader-versus-people model, the democratization of institutionalized politics and the integration of stronger participatory components in the relationship between leadership and people suffice. I would, though, argue that this is a very reductionist and problematic strategy as it's based on the reductionist assumption of unilaterality of the relationship between leader/regime and people. Instead, we will have to deploy different models that acknowledge the existence of a multi-layered set of relationships. This also brings the argument that it's not only a matter of increasing levels of participation in the field of institutionalized politics but also a matter of integrating participatory logics in all parts of society. And sometimes-interestingly enough-one particular field might be completely blocked from reform. It might be extremely difficult or virtually impossible to integrate more participatory dimensions into one particular field. There might be horrible forms of violence launched against those who try.

But then, thinking about how a participatory culture-and here Henry Jenkins reappears on the stage (laughs)-functions seems to offer different opportunities. Remember, a participatory culture spans across society, and does not privilege one particular societal field. A participatory culture has been established when the participatory intensities in all societal fields have been sufficiently enhanced and brought close to the maximalist intensities. This way of thinking is interesting, also at the strategic level in dealing with authoritarian regimes, because it might open up opportunities for hidden and maybe temporary democratization processes. These temporary autonomous zones, as Hakim Bey (1985) would call them, might go largely unnoticed by authoritarian regimes, because they are not considered of strategic importance. Of course, this type of strategy might be impossible to deploy in totalitarian regimes, as in these regimes all parts of society are controlled. But that is exactly the difference between authoritarian and totalitarian regimes: Authoritarian regimes leave 
gaps in their structures of control. These gaps can be found, and participation could be injected, if I can use a really bad metaphor. Participatory levels could be increased there, slowly enhancing and spreading a more participatory culture.

I would argue that it is a matter of bypassing the unilateral perspective and looking at various particular areas. Here, we can also attribute a role to alternative media, because they are sites of alternative ways of thinking about power. And they are sites of participatory-agonistic logics. They are often participatory-agonistic assemblages that can grow and that can offer a rhizomatic alternative to an authoritarian regime. I am not saying that this is easy and safe. As this analysis is made on a wonderful, slightly hard bench at Complutense University in Madrid, I should be careful not to sound as if the problem will be solved tomorrow, without any cost. These strategies are still dangerous and can sometimes be destructive for those who deploy them, but I do think that they can produce alternative solutions, contributing to the realization of what the starting point of my entire argumentation was: the need to hegemonize democracy and agonism.

DY: My last question. In your conversations and discussions, you talk about this "participatory-democratic" imaginary and the role and responsibility of intellectuals in building this imaginary. How do you articulate the role of academia and intellectuals, who are of course not only in academia? Specifically, what do you think about the role of academia and academics in this process?

NC: My starting point would be a fairly dystopian analysis of the current global state of democracy, which was also discussed in the 2019 conversation with Henry (Jenkins and Carpentier, 2019b). And agonisms, actually, but let's focus on democracy. What we are seeing now is not only the crisis of representative democracy. What we are witnessing now is the crisis of the idea of democracy. We've seen throughout the Western world a whole range of authoritarian regimes being established, apparently finding the strength to maintain themselves. I should add an immediate disclaimer. There is a deeply problematic component in my last statement, in the sense that other parts of the world have been exposed to non-democratic regimes for a very long time. Often, we just shrugged our shoulders, or, tried to impose formal democratic models-mirror-imaging those in the West-that were bound to fail. Only now, when we are being confronted with this problem from nearby, in the West itself, all possible alarms start going off. We might have done that earlier. We haven't. The alarm bells should be ringing nevertheless. We should acknowledge that anti-democratic forces are gaining strength 
in the West. And if we are in favour of the hegemonization of democracy, this is a serious threat, because these forces are aiming to cancel democracy as an idea. My analysis here is driven by a deep concern for the future of democracy at the global level, maybe focusing a bit too much on Europe and North America - as I know these regions best-but without excluding other parts of the world.

One of the main answers to this problematization would be that we urgently need the creation of what I would like to call "a new social contract" on democracy, driven by an alliance of all democratic forces, conservative and progressive, left and right. All those who care about the idea of democracy in its wide variety of articulations and operationalizations, need to endorse democracy, as a social contract. This creation of an alliance is a very Gramscian idea, of course. Or in Laclau and Mouffe's (1985) terms, it's the creation of a chain of equivalence that defends the idea of democracy. In parallel, there is also a need for the creation of a second alliance, one that defends a number of progressive ideas. And there, in order to support that second alliance, we need to create a radical progressive utopia for the 21st century. A cluster of neoliberal, nationalist and racist projects exists, despite the many complexities and contradictions that characterize this cluster. But on the left flank, a very defensive position has been taken, and we lack a fully developed left-wing, radically progressive ideological project, that can also be clearly communicated. Mouffe (2019) uses the concept of populism as a nodal point for this project of ideological articulation. Her argument is an argument for the development of a left populism. We can argue about terminology, but that is not relevant here. We need to create a progressive chain of equivalence that develops a new progressive ideological project, learning from the horrible mistakes from the past, and focusing on how to create an ideology of democracy, agonism, peace, empowerment and social justice.

That brings me to your question about intellectuals. I want to echo something that was in your question. There is a structural difference between intellectuals and academics, in the sense that intellectuals are a much broader concept. Obviously, there are also intellectuals that are non-academics. We should never underestimate the nonacademic parts of our societies, and their capacity to function as fields of knowledge production. In other words, we, academics, should not articulate academia as an exclusive site of knowledge production. That would be a really strong case of hubris, and I think we need to avoid that. So I like to talk about intellectuals, knowing that in many cases academics will take on that role and that identity, but also many others will. 
My point would be-and this comes out of an article, which is called A Call to Arms, published in Javnost (Carpentier, 2014) - that intellectuals have a key role to play in the creation of this progressive ideological framework. That article from 2014 tries to think through the practicalities of the collaborative work needed to create this kind of ideological framework, as the hyper-specialized positions some intellectuals take don't necessarily help for the creation of a very broad ideological project that also needs to have sophistication combined with communicative simplicity.

Nevertheless, this collaboration is necessary. In developing this progressive ideological framework, I would argue that a modular approach might work. This implies that different intellectuals, and clusters and groups of intellectuals, grounded in their fields of study and their specializations, might need to mobilize to think through the nature of this ideological framework and to imagine how that progressive ideology would look like. These different components, or modules, can then be articulated into an ideological project which can then be communicated and can become an ideological intervention. Obviously, in practice, this will never result in one clear and homogenous model; but the process of ideology creation already matters significantly, and the resulting ideological trajectories can definitely contribute to providing an ideological backbone for political action.

That brings me back-and this is the last part of my answer-to my starting point (laughs): The need for a new social contract for democracy because I think that also there intellectuals and academics can contribute to strengthening and enabling that alliance. There is a tradition when it comes to academics that have been active in the peace movement, trying to build bridges, for instance, between the East and West during the period of the Cold War, trying to prevent the implementation of the MAD strategy - where MAD stood for "Mutually Assured Destruction". We can look at the Russell-Einstein Manifesto from the mid-1950s, which pointed to the threat of nuclear weapons for humanity in its entirety, with the famous sentence "Remember your humanity, and forget the rest." That Manifesto was translated in the Pugwash Conferences which focused on reducing the dangers of violent conflict. You might remember that the Pugwash Conferences won the Nobel peace prize in 1995. And if we stick to Bertrand Russell, and go a bit further back in time, we should not forget his pacifism in the run-up to, and during, the First World War. His deep commitment to peaceful coexistence in Europe resulted in his dismissal from the Trinity College at Cambridge University in 1916, and in a six-month prison sentence in 1918. These are the 
examples of contributions of intellectuals in the hegemonization of democracy and agonism, and we should remember and honour them.

One last example-now that we are at the IAMCR conference-we should not forget that also IAMCR, as an organization with an existence of over 50 years, has intensely contributed to bringing together different voices from all around the world, also during the Cold War, where scholars from the Soviet Union, from Western Europe, from East Germany and from West Germany actively engaged with each other, in sometimes difficult, sometimes less difficult dialogues. These are the examples that can be seen as embryos of the development of a new social contract for democracy. And we, as intellectuals and academics, do have a role to play. It is not an exclusive role, but we are actually quite well-armed-to abuse a military metaphor-to organize and to engage in these dialogues. Because we have built these bridges across countries, across nations, across power blocks that are becoming more and more antagonistic.

So, yes, we do have a very, very significant role to play, at these different levels.

DY: Thank you very much!

\section{References}

Bey, H. (1985). The Temporary Autonomous Zone, Ontological Anarchy, Poetic Terrorism. Brooklyn: Autonomedia.

Carpentier, N. and Doudaki, V. (2019a). Critiquing Hegemony and Fostering Alternative Ways of Thinking About Homelessness: The Articulation of the Homeless Subject Position in the Greek Street Paper shedia, Communications. Media. Design, 4(1): 5-31. Available online: https://cmdjournal.hse.ru/article/view/10604.

Carpentier, N. and Doudaki, V. (2019b). The Construction of the Homeless in the Greek Street Paper shedia, in Maria Francesca Murru, et al. (eds.) Communication as the Intersection of the Old and the New. Bremen: edition Lumière, pp. 85-103. Available online:

http://www.researchingcommunication.eu/book14chapters/CH07_DOUDAKI2018 19.pdf.

Carpentier, N. (2019). Mirror Palace of Democracy, in Nico Carpentier (ed.) Respublika!:

Experiments in the Performance of Participation and Democracy, Limassol: NeMe, pp. 
146-153. Available online: http://uu.diva-

portal.org/smash/get/diva2:1271071/FULLTEXT01.pdf.

Carpentier, N. (2017) The Discursive-Material Knot: Cyprus in Conflict and Community

Media Participation. Bern, Switzerland: Peter Lang.

Carpentier, N. (2016). Beyond the Ladder of Participation: An Analytical Toolkit for the

Critical Analysis of Participatory Media Processes. Javnost: The Public, 23 (1), 70-88.

Available online: http://dx.doi.org/10.1080/13183222.2016.1149760.

Carpentier, N. (2014). A Call To Arms. An Essay on the Role of the Intellectual and the

Need For Producing New Imaginaries. Javnost - The Public, 21(3): 77-92.

Carpentier, N. and Van Brussel, L. (2012). Using Discourse Theory: A Discourse-

Theoretical Exploration of the Articulation of Death, in Ilija Tomanić Trivundža, et al. (eds.) Critical Perspectives on the European Mediasphere. The Intellectual Work of the 2011 ECREA European Media and Communication Doctoral Summer School. Ljubljana:

Faculty of Social Sciences, pp. 57-68. Available online:

http://www.researchingcommunication.eu/Book7_Carpentier_VanBrussel.pdf.

Carpentier, N. (2011) Media and Participation. A Site of Ideological-Democratic Struggle.

Bristol: Intellect. Available online:

https://oapen.org/download?type=document\&docid $=606390$.

Doudaki, V. and Carpentier, N. (eds.) (2018). Cyprus and its Conflicts: Representations, Materialities, and Cultures. New York: Berghahn.

Jenkins, H. and Carpentier, N. (2013). Theorizing Participatory Intensities: A Conversation About Participation and Politics. Convergence, 19(3), 265-286.

Jenkins, H. and Carpentier, N.(2019a). Participatory Politics in an Age of Crisis. Part I [5 blog posts]. Part 1 available online:

http://henryjenkins.org/blog/2019/5/30/participatory-politics-in-an-age-of-crisishenry-jenkins-amp-nico-carpentier-part-i.

Jenkins, H. and Carpentier, N. (2019b). Participatory Politics in an Age of Crisis. Part II [5 blog posts]. Part II available online: http://henryjenkins.org/blog/2019/5/30/participatory-politics-in-an-age-of-crisishenry-jenkins-amp-nico-carpentier-part-ii-gr9de.

Laclau, E. and Mouffe, C. (1985). Hegemony and Socialist Strategy: Towards a Radical Democratic Politics. London: Verso. 
Lepik, K. (2013). Governmentality and Cultural Participation in Estonian Public Knowledge Institutions. PhD thesis. University of Tartu Press, http://hdl.handle.net/10062/32240.

Mouffe, C. (2019) Toward a Left Populism. London: Verso.

Tomanić Trivundža, I., Nieminen, H., Carpentier, N., and Trappel, J. (eds.) (2018). Critical Perspectives on Media, Power and Change. London: Routledge.

Van Brussel, L, Carpentier, N. and De Cleen, B. (eds.) (2019). Communication and Discourse Theory: Collected Works of the Brussels Discourse Theory Group. Bristol: Intellect. 